\title{
ANTIBACTERIAL AND ANTIFUNGAL ACTIVITY OF HEDYOTIS CORYMBOSA, INULA RACEMOSE, HOLOSTEMMA ADAKODIEN MEDICINAL PLANTS
}

\author{
AJIT KUMAR MARISETTI*, VENKATARATHANAMMA V. \\ Department of Zoology, Acharya Nagarjuna University, Nagarjunanagar, Andhra Pradesh, India \\ Email: ajitkmarisetti@gmail.com
}

Received: 14 Nov 2018, Revised and Accepted: 20 Feb 2019

\begin{abstract}
Objective: To evaluate the antibacterial and antifungal activity of three different medicinal plants invitro. Oil extracts of the plants from three different families (Hedyotis corymbosa, Inula racemose, Holostemma adakodien) are used to find the antibacterial and antifungal activity.

Methods: Study of anti-microbial activity using agar cup diffusion method, inoculums preparation, Anti-bacterial activity screening (well diffusion method), Anti-fungal activity screening (well diffusion method) are the different methods which are used to find the anti-bacterial and anti-fungal activities of the oil extracts of the above medicinal plants. The activity of these oil extracts and the selected antibiotics are evaluated against four bacterial strains (E. Coli, S. aureus and P. aeruginosa) and three Candida fungal strains (albicans, parapsilosis and tropicalis.). The anti microbial activity of Hedyotis corymbosa, Inula racemose, Holostemma adakodien oil extracts zone of inhibition evaluation was compared with positive control of fungal strain Fluconozole and bacterial strain Norfloxacin, Cefepime and Gatifloxacin.
\end{abstract}

Results: The anti microbial activity of Hedyotis corymbosa, Inula racemose, Holostemma adakodien oil extracts zone of inhibition evaluation was compared with positive control of fungal strain Fluconozole and bacterial strain Norfloxacin, Cefepime and Gatifloxacin. Further studies are needed to explore the novel antibacterial bioactive molecules.

Conclusion: The plants Hedyotis corymbosa, Inula racemose and Holostemma adakodien have shown significant anti-bacterial and anti-fungal activity.

Keywords: Microbial activity, Hedyotis corymbosa, Inula racemose, Holostemma adakodien

(C) 2019 The Authors. Published by Innovare Academic Sciences Pvt Ltd. This is an open access article under the CC BY license (http://creativecommons.org/licenses/by/4.0/) DOI: http://dx.doi.org/10.22159/ijcpr.2019v11i2.33018

\section{INTRODUCTION}

The development of new synthetic anti-microbial drugs was slow down due to the increase in prevalence of multiple drug resistance. This necessitated the research of new alternative anti-microbial sources. Medicinal plants represent a rich source of anti-microbial agents and posses varied medicinal properties. Compounds from medicinal plants showing antimicrobial activities have the potential of filling this need, because their structures are different from those of the more studied microbial sources, and therefore their mode of action are also very likely to differ. Traditional medicinal practice is an important part of the primary health care system in most of the developed as well as developing countries. Nearly, there are 1.5 million practitioners of traditional medicinal system who are using medicinal plants in preventive, promotional and curative applications. According to a report stated by World Health Organization that approximately 3.5 billion people in the developing countries depends on the plants for their primary health care. Many rural and some urban people belonging to the interior parts of India still depends on the herbs for their medicinal practice [1].

It has been estimated that the local communities (Tribal people) have used about $10 \%$ of flowering plants on earth for treating various diseases, and infections, although only $1 \%$ have been scientifically proven by modern scientists, Plants are rich source with a wide range of secondary metabolites such as tannis, alkaloids, flavanoids and number of bio-active compounds which were proven to have an efficient in vitro anti-microbial activity [2] A number of Phytotherapy manuals are also available to support the above mentioned statement that medicinal plants have been used in treating various infectious diseases. This is because of the reason that the medicinal plants are ubiquitous, with fewer side effects and have low toxicity. According to WHO, medicinal plants would be the best source for obtaining variety of drugs and this evidence support to quantify the importance of screening natural products [3] Though, several numbers of plants have been tested for anti-microbial property using plant extracts the vast majority of them has not been evaluated using their essential oils [4]. The potential activity of medicinal plants against microbes depends on the nature of the plant drug either in crude form or as an isolated compound. It offers a hope and fulfills its role in curing microbe's related diseases. Among few countries, India is the one which is having unique wealth in medicinal plants and vast traditional knowledge of using herbal medicine for curing various diseases. So far only a fewer species of plants has been tested thoroughly for their anti-microbial activity using crude extracts. At the same time, those plant's which showed an efficient antimicrobial activity by their extracts has to tested whether the same range of activity is obtained while using their essential oils of the same plants and till now this sort of studies in lacking [5].

Essential oils and their components are becoming increasingly popular as natural anti-microbial agents and it is used for a wide variety of purposes including food preservation, complementary medicine and natural therapeutics. So far, essential oils are used extensively in flavoring industry for flavor enhancement and for their anti-oxidant effects but, their potential use as anti-microbial agents is unexplored [6]. Burt in his review report stated that a plant's essential oils is obtained from a specialized cells or glands found in the specialized organs such as seed, flowers, leaves and stem of the plants and are usually obtained by distillation methods. Most of the essential oils contains the mixture of compounds mainly terpenoids (Specifically monoterpenes, sesquiterpenes and diterpenes) [7]. Another, review by Faleiro stated that the antimicrobial activity exhibited by an essential oil is not due to the presence of a single compound, but it may be due to the synergistic activity of different compounds [8]. Hence, there prevails a need for study on the essential oils of plants for new anti-microbial agents. Use of antibiotics is the commonly known therapy for microbial infections (Bacteria and Fungi). But, the over usage of this antibiotics has become the major factor for the emergence and dissemination of multi-drug resistance strains of several group of micro-organisms. In addition to this serious problem with multi drug resistance (MDR) strains, antibiotics are sometimes associated with the adverse effects on the host which includes hypersensitivity, immune 
suppression and allergic reaction. Due to this reasons researches are now increasingly turned their attention to herbal products, to develop a better and a new drug against MDR microbial strains [9]. Considering, these vast potentiality of plants essential oil as a source of anti-microbial drugs, we intended to study the anti-microbial activity of the selected three study plant's essential oil with reference to its corresponding standard anti-bacterial and antifungal drugs in the present study.

\section{Objective}

To evaluate in vitro anti-microbial activity of Hedyotis corymbosa, Inula racemose, Holostemma adakodien essential oils.

\section{Rationale}

The selected plants contained the pharmacologically important compounds which were already reported to have anti-microbial activity by various studies. Also these plants are traditionally used for treating minor ailments such as common cold, wound healing, antipyretic and anti-tumour. Hence we need to study the antimicrobial activity of the essential oil of these plants to validate scientifically.

\section{Hypothesis to be analysed}

The selected medicinal plant's essential oil possess a tri-terpenes which are capable of breaking or destabilizing microbial cell membranes and thereby killing/attenuating them. Thus the selected plant's essential oil may have anti-microbial activity with equal or higher potency that the existing study chemical agents.

\section{MATERIALS AND METHODS}

\section{Study of anti-microbial activity}

The study of anti-microbial activity of essential oil was done by using agar cup diffusion method. Under aseptic condition, the well was filled with $50 \mu \mathrm{l}$ of essential oil for this study as per the available literature on the study on essential oil $[11,12]$.

\section{Inoculum preparation}

The bacterial and fungal cultures were obtained from National Centre for Cell Science (NCCS), Pune. The bacterial cultures were Escherichia coli, Staphylococcus aureus, Pseudomonas aeruginosa, Streptococcus pneumonia and the fungal cultures were Candida albicans, Candida tropicalls and Candida parapsilosis. The bacterial cultures were maintained in nutrient broth and nutrient agar slants. The fungal cultures were maintained in potato dextrose agar plates and slants. It was further sub cultured before use. The mother inoculums was maintained at $37^{\circ} \mathrm{C}$ for about $24 \mathrm{~h}$ (bacteria) and 48 to $72 \mathrm{~h}$ (fungi). The bacterial and fungal strains were scooped out by adding sterile distilled water. The fungal and bacterial strains were collected to about $1 \mathrm{ml}$ and it was serially diluted from $10^{-1}$ to $10^{-6}$ and plating was made using $10^{-6}$ dilution for bacterial and $10^{-4}$ for fungal inoculum.

\section{Anti-bacterial activity screening (Well diffusion method)}

The well diffusion method was employed for the determination of anti-bacterial activities of the essential oil of the selected medicinal plants $[10,13]$. The culture medium was allowed to set thereafter, a sterile cork borer ( $6.0 \mathrm{~mm}$ diameter) was used to punch the wells in the seeded nutrient agar. The agar plugs were removed and well was filled with $0.1 \mathrm{ml}$ of the various test items, which had been surface spread with $0.1 \mathrm{ml}$ of bacterial suspension adjusted to $10^{-6}$ Colony Forming Units $(\mathrm{CFU}) / \mathrm{ml}$ for all the selected bacteria (Escherichia coli, Stahylococcus aureus, Pseudomonas aeruginosa, Streptococcus pneumonia). The standard antibiotics such a Norfloxacin $10 \mu \mathrm{g}$, Cefepime $30 \mu \mathrm{g}$ and Gatifloxacin $5 \mu \mathrm{g}$ were used as positive controls. The plates were conducted in triplicates and incubated at $37 \pm 1{ }^{\circ} \mathrm{C}$ for 24 to $48 \mathrm{~h}$ and zone of inhibition was measured millimeters. Tests were carried out in triplicates.

\section{Anti-fungal activity screening (well diffusion method)}

The well diffusion method was employed for the determination of antibacterial activities of the essential oil of the selected medicinal plants [10, 13]. The culture medium was allowed to set thereafter, a sterile cork borer ( $6.0 \mathrm{~mm}$ diameter) was used to punch the wells in the seeded nutrient agar. The agar plugs were removed and well was filled with 0.1 $\mathrm{ml}$ of the various test items, which had been surface spread with $0.1 \mathrm{ml}$ of fungal suspension adjusted to $10^{-4} \mathrm{CFU} / \mathrm{ml}$ for the selected fungal species (Candida albicans, Candida parapsilosis, Candida tropicalis). Potato Dextrose Agar (PDA) plates, without essential oil were used as negative control and the one treated with standard antibiotic (Fluconozole $25 \mu \mathrm{g}$ ) was used as positive control. After incubation at $25 \pm 2{ }^{\circ} \mathrm{C}$ during $48 \mathrm{~h}$, the diameters of inhibition zones were measured in millimeters. Tests were carried out in triplicates.

\section{RESULTS}

\section{Anti-microbial activity}

$100 \mu \mathrm{g} / \mathrm{ml}$ of all the selected three study plants was identified as the minimal and optimal dose to inhibit the growth of the microorganisms with a measurable clear zone of inhibition. The diameter $(\mathrm{mm})$ of the zone of the inhibition (ZOI) has been studied for the determination of anti-microbial activity for both antibacterial and anti-fungal activity of the essential oil of the selected study plants and the results were compared with that of for the standard antibiotics.

Table 4.1 and fig. 4.1 shows the anti-bacterial activity of the essential oils where, the essential oil of Holostemma adakodien showed the highest zone of inhibition for all the bacteria tested such as Escherichia coli $(21.7 \pm 1.4 \mathrm{~mm})$, Streptococcus pneumonia $(23.5 \pm 1.5$ $\mathrm{mm})$, Pseudomonas aeruginosa $(24.9 \pm 1.3 \mathrm{~mm})$ and Staphylococcus aureus $(25.4 \pm 1.1 \mathrm{~mm})$ when compared with the essential oil of Hedyotis corymbosa and Inula racemose. The ZOI are more or less equal to the zone of inhibition of the standard antibiotics such as Cefepime, Gatifloxacin and Norfloxacin.

However, the essential oils of Hedyotis corymbosa and Inula racemose also has shown a good anti-bacterial activity though less as follows: The essential oil of Inula racemose showed a zone of inhibition to about $19.7 \pm 1.4 \mathrm{~mm}$ for Escherichia coli, $19.3 \pm 1.9 \mathrm{~mm}$ from staphylococcus aureus, $17.2 \pm 1.2 \mathrm{~mm}$ for streptococuccus pneumonia; for Pseudomonas aureginosa $17.7 \pm 1.5 \mathrm{~mm}$. The essential oil of Hedyotis corymbosa showed a zone of inhibition to about $19.3 \pm 1.1 \mathrm{~mm}$ for Escherichia coli for Staphylococcus aureus $18.1 \pm 1.5$ $\mathrm{mm}$ for Pseudomonas aureginosa as $19.2 \pm 1.3 \mathrm{~mm}$ and for Streptococcus pneumonia as $17.7 \pm 1.7 \mathrm{~mm}$.

The anti-fungal activity of the essential oil was expressed in terms of zone of inhibition against the selected fungal species and compared with the standard anti-fungal ccompound Fluconozole. Table 4.2 and fig. 4.2 shows the anti-fungal activity of the essential oil in which the ZOI of all the three study plants are almost similarly (ranging from 12-16.3 $\mathrm{mm} \pm 1.7-1.6)$ and more or less equal to the ZOI of Fluconozole against the 3 fungal strains tested $(17 \mathrm{~mm} \pm 1.6)$ against Candida albicans, $(18.3 \mathrm{~mm} \pm 1.5)$ against Candida parapsilosis and $(16.6 \mathrm{~mm} \pm 2.2)$ against Candida tropicalis.

Table 1: Anti-bacterial activity of the essential oils of the selected study plants

\begin{tabular}{|c|c|c|c|c|c|c|}
\hline \multirow{3}{*}{$\begin{array}{l}\text { Bacterial } \\
\text { strains }\end{array}$} & \multicolumn{6}{|c|}{ Zone of Inhibition expressed in mean \pm standard deviation of 3 values (mm) } \\
\hline & \multirow{2}{*}{$\begin{array}{l}\text { Hedyotis corymbosa } \\
(100 \mu \mathrm{g})\end{array}$} & \multirow{2}{*}{$\begin{array}{l}\text { Inula racemose } \\
(100 \mu \mathrm{g})\end{array}$} & \multirow{2}{*}{$\begin{array}{l}\text { Holostemma adakodien } \\
(100 \mu \mathrm{g})\end{array}$} & \multicolumn{3}{|c|}{ Positive Control } \\
\hline & & & & $\begin{array}{l}\text { Norfloxacin } \\
(10 \mu \mathrm{g})\end{array}$ & $\begin{array}{l}\text { Cefepime } \\
(30 \mu \mathrm{g})\end{array}$ & $\begin{array}{l}\text { Gatifloxacin } \\
(5 \mu \mathrm{g})\end{array}$ \\
\hline E. Coli & $19.3 \pm 1.1$ & $19.7 \pm 1.4$ & $21.7 \pm 1.4$ & $25.3 \pm 1.2$ & $23.9 \pm 1.4$ & $26.0 \pm 1.1$ \\
\hline S. aureus & $18.1 \pm 1.5$ & $19.3 \pm 1.9$ & $23.5 \pm 1.5$ & $25.1 \pm 2.8$ & $22.2 \pm 1.7$ & $27.0 \pm 1.1$ \\
\hline P. aeruginosa & $19.2 \pm 1.3$ & $17.2 \pm 1.2$ & $24.9 \pm 1.3$ & $28.2 \pm 1.4$ & $25.7 \pm 1.1$ & $25.1 \pm 1.6$ \\
\hline S. pneumonia & $17.7 \pm 1.7$ & $17.7 \pm 1.5$ & $25.4 \pm 1.1$ & $27.6 \pm 1.1$ & $25.3 \pm 1.4$ & $26.1 \pm 1.2$ \\
\hline
\end{tabular}


Table 2: Anti-fungal activity of the essential oils of the selected study plants

\begin{tabular}{|c|c|c|c|c|}
\hline \multirow{3}{*}{$\begin{array}{l}\text { Fungal } \\
\text { strains }\end{array}$} & \multicolumn{4}{|c|}{ Zone of Inhibition expressed in mean \pm standard deviation of 3 values (mm) } \\
\hline & \multirow{2}{*}{$\begin{array}{l}\text { Hedyotis corymbosa } \\
(100 \mu \mathrm{g})\end{array}$} & \multirow{2}{*}{$\begin{array}{l}\text { Inula racemose } \\
(100 \mu \mathrm{g})\end{array}$} & \multirow{2}{*}{$\begin{array}{l}\text { Holostemma adakodien } \\
(100 \mu \mathrm{g})\end{array}$} & Positive control \\
\hline & & & & Fluconozole $25 \mu \mathrm{g}$ \\
\hline C. albicans & $13.8 \pm 1.8$ & $14.7 \pm 2.1$ & $14.8 \pm 1.8$ & $17.5 \pm 2.0$ \\
\hline C. parapsilosis & $14.3 \pm 2.5$ & $16.5 \pm 2.2$ & $15.2 \pm 2.7$ & $18.9 \pm 2.2$ \\
\hline C. tropicalis & $12.5 \pm 1.3$ & $13.9 \pm 1.8$ & $14.1 \pm 1.5$ & $16.0 \pm 1.4$ \\
\hline
\end{tabular}
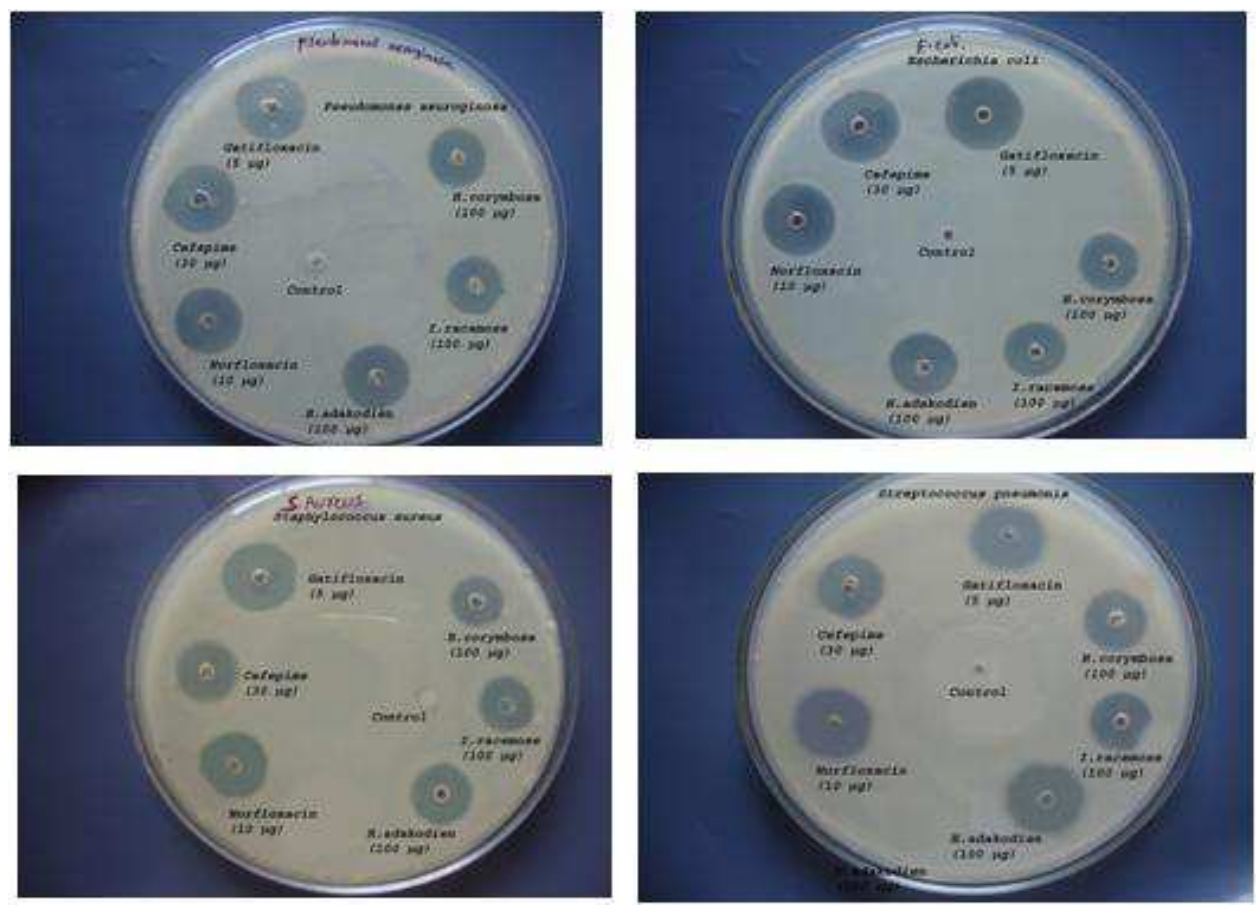

Fig. 1: Results for anti-bacterial activity of the essential oil
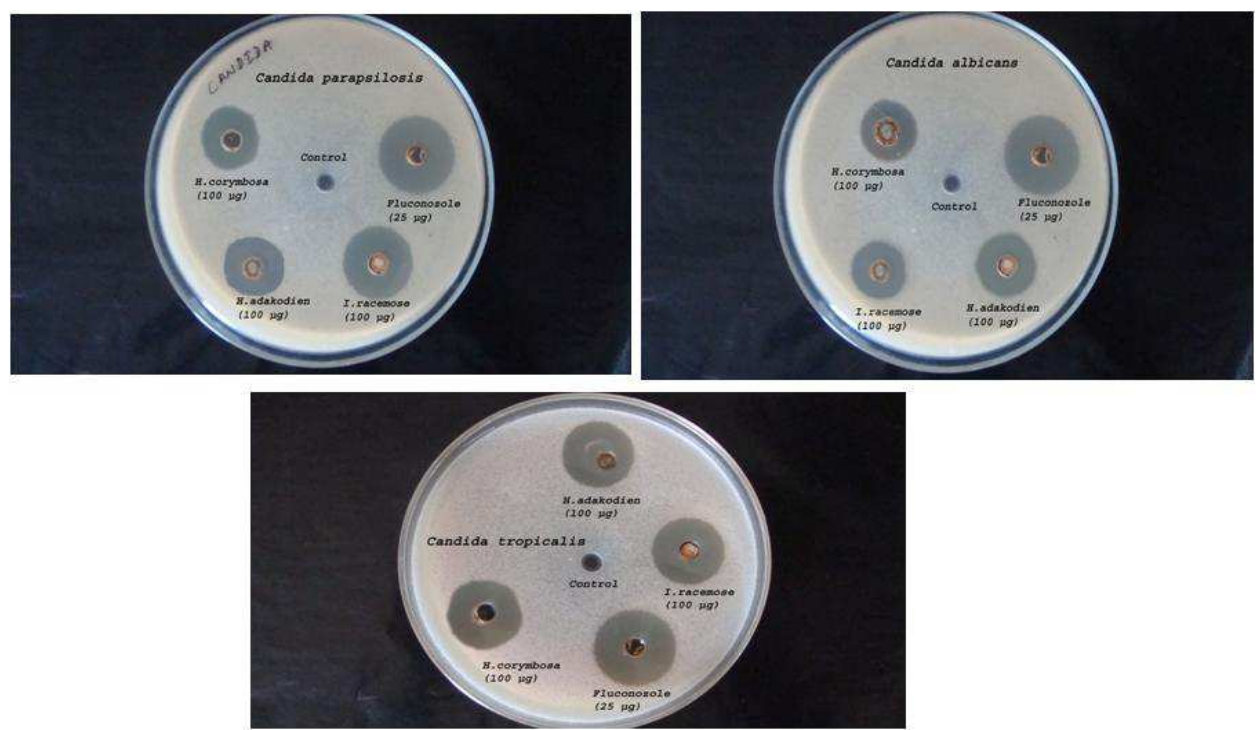

Fig. 2: Results for anti-fungal activity of the essential oil

\section{DISCUSSION}

Anti-microbial compounds. In general, essential oils are mixture of small organic bio-molecules generally hydrophobic in nature and are designated as naturally occurring antibiotics which may cause cytoplasmic membrane coagulation, breakdown of proton motive force, breakdown of electron flux and unbalance the active transport which are the some of the events that are responsible for effective anti-microbial activity of essential oils [15].

The current study aims on the determination of anti-microbial activity of the essential oils of these three selected medicinal plants against the pathogenic bacterial and fungal strains. The results were compared with the standard antibiotics. Researchers have 
determined the anti-fungal activity of essential oils from Indian medicinal plants against human pathogenic Candida spp, Cryptoccocus spp, Malassezia spp and Aspergillus spp [19]. A review article by Lahlou stated that, the essential oils are highly concentrated fluid substances and they are mostly used in an undiluted form which helps to slow down the rate of evaporation and to spread them evenly on the paper discs. He also stated that most of the anti-microbial studies carried out so far using plant's essential oil uses a dose range of

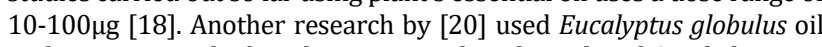
in their antimicrobial study against Escherichia coli and Staphylococcus aureus bacteria in different concentrations. Their study results concluded that a dose range of $100 \mu \mathrm{g} /$ well showed a better antibacterial activity (80\%) than the other doses used [20]. Based on these earlier research reports we have selected a dose of $100 \mu \mathrm{g} /$ well of essential oil for all the three plants and we found that this selected does was optimum for all selected microbial strains with a measureable clear zone of inhibition.

In the present study, we have examined the anti-bacterial activity of the selected plant's essential oil against two gram negative bacteria Escherichia coli, Pseudomonas aeruginosa and two gram positive bacteria Staphylococcus aureus, Streptococcus pneumonia respectively. Most of these strains are harmful and cause serious food poisoning in humans. We have also examined the anti-fungal activity of the selected essential oils against Candida albicans, Candida tropicalis and Candida parapsilosis which resides as commensal in the muco-cutaneous cavities of skin, vagina and intestine of humans. These fungus cause infections under altered physiological conditions (Immune compromised situations) such as infancy, pregnancy, diabetes, prolonged usage of antibiotics, steroidal chemotherapy during late stages of cancer as well as AIDS [16].

From the results of the study, it is clearly understood that all the three plants essential oil have shown its inhibitory activity against the selected micro-organisms but the range of inhibition differs from plant to plant. The plant Holostemma adakodien has shown the highest range of reported for its significant bio-activity against many bacterial and fungal infections in vitro [21].

Our next plant of interest Inula racemose belongs to the family Asteraceae. Different extracts of this plant has been reported for its significant and effective anti-microbial activity [20]. The study result shows that this essential oil has a significant anti-microbial activity when compared with the standard antibiotics. It showed an effective and significant anti-fungal activity which is relatively higher that anti-bacterial activity, which may be the reason for its traditional use for hair growth promoting properties and for treating dandruff. Moreover, as mentioned earlier in literature isoalantolactone in the essential oil of Inula racemose may be responsible for its significant anit-mircobial acitivty in which isoalantolactone enhance the antimicrobial activity [22].

The plant Hedyotis corymbosa is well known for its traditional usage for other diseases of the liver, heat eruptions, vitiated conditions of pitta, hyperdypsia, giddiness, dyspepsia, flatulence, colic, constipation, helminthiasis, leprosy, skin diseases, cough, bronchitis, necrosis, nervous depression caused by deranged bile and hepatopathy [24, 25]. Moreover, the plant has been documented by many researches that the extracts of both polar and non-polar solvent have a significant antimicrobial activity [26]. But, so far no research reports have documented about the anti-microbial activity of the essential oil of Hedyotis corymbosa. From the GC-MS analysis, the essential oil of Hedyotis corymbosa has shown the presence of major compounds such as asperuloside, oleanolic acid, rutin and $\gamma$-sitosterol.

In the present study, the significant and effective anti-microbial activity exhibited by the selected medicinal plants may be due to the presence of some of these major compounds in combination with the trace amount of other minor compounds too. From the present study results we could shoe that the plants that are levels of antimicrobial activity depends on the difference in their phytochemicals and major bioactive compounds.

\section{AUTHORS CONTRIBUTIONS}

All the author have contributed equally

\section{CONFLICT OF INTERESTS}

Declare none

\section{REFERENCES}

1. Idu M, Omonigho SE, Igeleke CL. Microbial load on medicinal plants sold in Bini markets, Nigeria. Indian J Traditional Knowledge 2008;7:669-72.

2. Khan R, Islam B, Akram M, Shakil S, Ahmad A, Ali SM, et al. Antimicrobial activity of five herbal extracts against multi drug resistant (MDR) strains of bacteria and fungus of clinical origin. Molecules 2009;14:586-97.

3. Santos PRV, Oliveira ACX, Tomassini TCB. Contole microbiogico de products fitoterapicos. Rev Farm Bioquim 1995;31:35-8.

4. Mahesh B, Satish S. Anti-microbial activity of some important medicinal plant against plant and human pathogens. World J Agric Sci 2008;4:839-43.

5. Renu G, Bandana T, Pushpendra S, Singh HB, Sharma VD, Katoch VM, et al. Anti-tuberculosis activity of selected medicinal plants against multi-drug resistant Mycobacterium tuberculosis isolates. Indian J Med Res 2010;131:809-13.

6. Rosangela DP, Vincenzo DF, Francesco V. In vitro anti-microbial activity of essential oil from Mediterranean Apiaceae, Verbenaceae and Lamiaceae against food borne pathogens and spoilage bacteria. Ann Microbiol 2005;55:139-43.

7. Burt S. Essential oils their anti-microbial properties and potential application in foods-a review. Int J Food Microbiol 2004;94:223-53.

8. Faleiro ML, Miguel MG, Laderio F. Anti-microbial activity of essential oils isolated from portuguese endemic species of thymus. Lett Appl Microbiol 2003;36:35-40.

9. Kaveri S, Vandana T, Rajneesh P. Study of anti-microbial activity of medicinal plants against various multiple drug resistance pathogens and their molecular characterization and its bioinformatics analysis of antibiotic gene from genomic database with degenerate primer prediction. Int J Biol Technol 2010;1:15-9.

10. Flora 0, Folasade D. Anti-microbial effect of phyllanthus amarus and parquetina nigrescens on salmonella typhi. Afr J Biomed Res 2008;11:215-9.

11. Mallappa KS, Mohd SA, Uma Rani S. Antimicrobial properties of plant essential oils against human pathogens and their mode of action: an updated review. J Evidence Based Complementary Altern Med 2016;1-21. http://dx.doi.org/10.1155/2016/3012462

12. Esmail Abdollahzadeh, Masoud Rezaei, Hedayat Hosseini. Antimicrobial activity of plant essential oils of thyme essential oil, nisin, and their combination to control Listeria monocytogenes inoculated in minced fish meat. Food Control 2014;35:177-83.

13. Hugo WB, Russell AD. Pharmaceutical microbiology. 5th ed Blackwell Scientific Publications, Oxford, London; 1992. p. 258-97.

14. Flora Oluwafemi, Folasade Debiri. Antimicrobial effect of phyllanthus amarus and parquetina nigrescens on salmonella typhi. Afr J Biomed Res 2008;11:215-9.

15. Aristides ML, Edeltrudes OL, Evandro LS. Inhibitory effect of $\alpha$ pinene, $\beta$-pinene and eugenol on the growth of growth of potential infectious endocarditis causing gram-positive bacteria. Braz J Pharm Sci 2007;43:121-6.

16. Amber Adams, Satyanshu Kumar, Marck Clauson, Shivendra Sahi. Anti-yeast activities of origanum oil against human pathogenic yeasts. Adv Biosci Biotechnol 2011;2:103-7.

17. Deriu A, Zanetti S, Sechi LA, Marongiu B, Piras A, Porcedda S, et al. Antimicrobial activity of Inula helenium L. essential oil against Gram-positive and gram-negative bacteria and candida spp. Int J Antimicrobial Agents 2008;31:588-90.

18. Lahlou M. Methods to study the phytochemistry and bioactivity of oils. Phytother Res 2004;18:435-88.

19. Eugenia P, Maria JG, Carlos C, Ligia S. Antifungal activity of Thapsia villosa essential oil against candida, cryptococcus, malassezia, aspergillus and dermatophyte species. Molecules 2017;22:1-11.

20. Bachir RG, Benali M. Antibacterial activity of these essential oils from the leaves of Eucalyptus globulus against Escherichia coli and staphylococcus aureus. Asian Pac J Trop Biomed 2012;2:739-42. 
21. Meena TI, Jolly CI, Sheela D. A study of the phytochemical composition and antibacterial activity of Holestemma adakodien schultes. Int J PharmTech Res 2011;3:1208-10.

22. Changhong Liu, Mishra AK, Bing He, Renxiang Tan. Antimicrobial activities of isoalantolactone, a major sesquiterpene lactone of Inula racemose. Chinese Sci Bull 2001;46:498-501.

23. Lokhande PD, Gawai KR, Kodam KM, Kuchekar BS. Antibacterial activity of isolated constituents and extract of roots of Inula racemosa. Rea J Med Plant 2007;1:7-12.
24. Sini Sadasivan, Latha PG, Sasikumar JM, Rajashekaran S, Shyamal S, Shine VJ. Hepatoprotective studies on hedyotis corymbosa (L) lam. J Ethanopharmacol 2006;106:245-9.

25. Warrier PK, Nambiar VPK, Ramankutty C. Indian medicinal plants-a compendium of 500 species. Vol. 3. Orient Longman Ltd. Chennai; 1995. p. 120-3.

26. Tamana S, Abdur RM, Ahad AM, Samsuddin FM. Hepatoprotective and antibacterial activity of ursolic acid extracted from hedyotis corymbosa L. Bangladesh J Sci Ind Res 2010;45:27-34. 